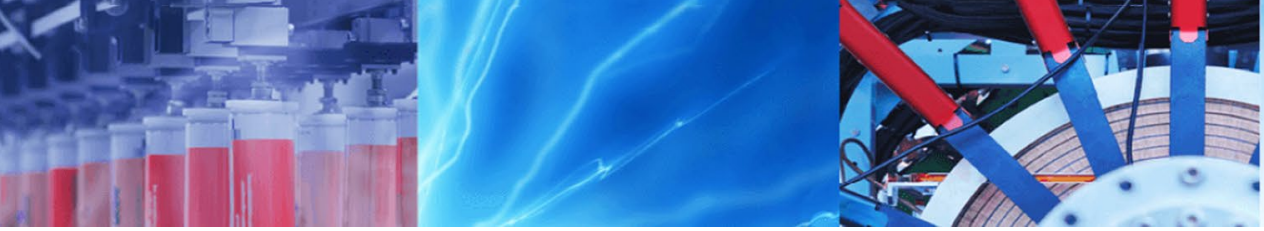

Research Article

\title{
Performance evaluation of municipal services with fuzzy multi-criteria decision making approaches: a case study from Turkey
}

\author{
Seyma Ozdogan ${ }^{1}$ (D) Abdullah Yildizbasi ${ }^{2} \cdot$ Babak Daneshvar Rouyendegh $^{2}$
}

Received: 27 November 2019 / Accepted: 28 April 2020 / Published online: 11 May 2020

(c) Springer Nature Switzerland AG 2020

\begin{abstract}
Performance evaluation is a multi-criteria decision making subject to assign effective municipal services. Municipalities are the organizations that see the common needs and services of a city or county, and the person in charge of the municipal administration is called the "mayor."The biggest duty of the mayor is to create an atmosphere of peace for the residents of the town where it is located, to respond to the needs of the town and the public and to conduct appropriate meetings. Mayors must meet all the requirements to make his/her town better and more functional. However, it is also not possible and takes a long time to meet all the needs of the people at the perfect level because of limited sources that municipalities have. Therefore, mayors should prioritize the tasks that can satisfy the public the most among the services they offer to the public. In this study, the fuzzy analytic hierarchy process and fuzzy technique for order preference by similarity to ideal solution methods, which are widely used in the literature, were used for the prioritization of the municipal services. This study is expected to shed light on mayors with limited resources to increase public satisfaction in the short term.
\end{abstract}

Keywords Municipal service selection · Multi-criteria decision making · Fuzzy TOPSIS · Fuzzy AHP

\section{Introduction}

Municipalities, which are the most important units that can serve society directly, try to carry out their works in a certain order to produce more quality and effective services. However, municipalities are one of the most complex and difficult sub-systems in the service sector, as they have many duties and responsibilities [1]. The person responsible for the management of the municipalities is the mayor elected by the local people. Mayors are trying to deal with limited resources with this management challenge. The purpose of the mayors in the management process is to increase the level of public welfare, to please the people and to regain the mayor elections in the next elections.
However, municipalities cannot give equal importance to all services due to their limited resources such as economic insufficiency, insufficient personnel, and lack of tools, equipment or materials.

The difficulties experienced by the municipalities in prioritizing their services to keep the satisfaction and prosperity of the people at the highest level have created an idea for this study. In line with this idea, the services provided by the municipalities were determined based on the laws of the countries and by discussing with the municipalities. For the services to be implemented, a numerical method was needed as there were different contradictory criteria. Since multi-criteria decision-making techniques consist of approaches and methods that try to reach the most appropriate solution that meets multiple criteria that

Seyma Ozdogan, seyma.ozdogan@gidatarim.edu.tr; Abdullah Yildizbasi, ayildizbasi@ybu.edu.tr; Babak Daneshvar Rouyendegh, babek.erdebilli2015@gmail.com | 'Department of Industrial Engineering, Konya Food and Agriculture University, 42080 Konya, Turkey. ${ }^{2}$ Department of Industrial Engineering, Ankara Yıldırım Beyazıt University (AYBU), 06010 Ankara, Turkey. 
conflict with each other, it is aimed to reach the result with these multi-criteria decision-making (MCDM) methods [9].

In line with the objective of the study, not all services included in municipal laws were used in the study. The number of services to be used in the study was determined as five according to the public interest and their views by interviewing the experts working in the public services units in a municipality in Turkey. Considering the experts, who are responsible for local people's satisfaction in municipalities, ideas the five most important services are chosen from the literature and experts opinion. The selected services can be defines as emergency services, infrastructure services, social services, recycling and waste management services, and parks, gardens and landscape services [2].

The poor quality of emergency services makes people feel insecure and they become negative about management because this service is vital for people. Examples for emergency services are municipal police, fire brigade, emergency aid, ambulance, hospital services, search and rescue. About infrastructure services, infrastructure consists of facilities for providing services such as electricity, gas, drinking and utility water, sewerage, communication and treatment, as well as indoor and outdoor parking facilities. Infrastructure services have great importance in the state economy as far as it is important to people [4].

The municipalities must follow aging infrastructure systems, new regulations, distributed energy sources and technologies and carry out the necessary work. Infrastructure services include transportation services. In daily life, many people use the vehicle of transportation to go to work, school, hospital, etc., but in any glitches in transportation people become unhappy. To provide easy and safe transportation, municipalities prepare the project for intercity and urban transportation roads, traffic, public transport, bus stations, bus schedule plan, implement these projects to areas which are included in the municipality and do maintenance and repair activities. Services such as enabling people to spend their free time with social activities, providing social communication and cultural development among people, increasing common areas to share with the local area, providing sports activities to people, helping people solve their problems, organizing panels and seminars to involve the public in social life, and making citizen's lives healthy are municipal services that include social services [3].

Municipalities raise awareness of people to recycling, make ads that explain the importance of recycling and make projects for increasing recycling. Parks, gardens and landscape services are the last of the five most important services since within the borders of the municipality, the municipality is responsible for the greening activities to ensure the visual beauty of the streets [2]. Also, the municipality makes the necessary arrangements for the planning of the urban area under the economic opportunities, the needs of the people, the aesthetic rules and the environment [3].

The impact of these selected services on regional development has been weighted by experts, taking into account the criteria such as the needs of the public, the number of employees to be used while providing the service, the usefulness of the job, the cost and the economic contribution or damage. Using the FAHP and FTOPSIS methods, which are the most used MCDM methods based on the criterion weights, it was determined which municipalities should give priority to the services to satisfy the public.

\section{Literature review}

Within the scope of this study, a literature review was conducted to show current attempts to evaluate municipal services with the FAHP and FTOPSIS method. The relevant literature is divided into two sections as follows: (1) studies that integrate the MCDM method into the services provided by the municipalities and (2) studies using the FAHP and FTOPSIS methods.

Literature research on the evaluation of municipal services with MCDM methods shows that in the last two decades no studies have been conducted on the link between municipal services. For this reason, this issue has been recognized as a deficiency in the literature and this study has been done.

There are some studies about municipal services or MCDM methods in Municipality. Bostancı [2] has assessed criteria (reconstruction and city planning, firefighting services, road and sidewalk construction, cemetery services, traffic and junction arrangements, veterinary services, public transport services, police services, parking services, formal relations, wastewater and sewage services, contact, quality of potable water, social benefits, waste and environmental cleaning, cultural events, parks and gardens, social events, sports facilities, and sports activities, municipal social facilities) and found fuzzy analytical hierarchy process (FAHP) and criteria weight, and eventually, a single nominal value has been calculated per each individual by using the answers to the questionnaires. Kılıç [3] aims to assess the performance of the municipalities with VIKOR multi-criteria decision-making method where nearness to the ideal solution is regarded. For this aim, an application is performed among the municipalities in Istanbul and municipality which is better than the others is found. The factor of solid waste collection, the ratio of expenses for education, culture and public relations in total cost, the capacity of producing income, the number of staff in fire department per 1000 citizens, the ratio of management 
cost in total cost, the number of administrative personnel, the indicator for environment protection and the administrative efficiency are taken into account as criteria. Çiçek and Dikmen [4] analyze the performance of municipalities in terms of expenditure structures. Top ten provincial municipalities in terms of per capita spending are analyzed through grey relational analysis (GRA) technique with criteria which are general public services, defense services public order and security services, economic affairs and services, environmental protection services, public and social welfare services, health services, restoration culture and religious services, education services, social security and social assistance services. Bozdoğan et al. [1] evaluate the financial performance of the five metropolitan municipalities with six-year financial data that have been evaluated by multi-criteria decision-making methods AHP and TOPSIS. Four main criteria (liquidity ratios, budget rates, long-term debt payment competency ratios, service sustainability ratios) taken by Wang's study are used with 11 sub-criteria belonging to these main criteria. Zarei and Talebnia [5] make performance evaluation of the Tehran municipality regions by GAHP (group analytic hierarchy process)-VIKOR (VIse Kriterijumsa Optimizacija I Kompromisno Resenje) techniques based on three areas; "finance," "growth and development" and "citizens." Ansari et al. [6] aimed at evaluating the performance of Qazvin municipalities. FMCDM (fuzzy multi-criteria decision making) approach is used which is based on four dimensions of the balanced scorecard (BSC) model (internal processes, the customer (citizen) dimension, the financial dimension, the dimension of learning and development) to find the most important dimension among the four dimensions of BSC. There are many applications of multi-criteria decision methods in the literature, but studies on the evaluation of municipal services with the MCDM method are as in Table 1. The literature study shows that there are not many studies in the literature about the application of FAHP and FTOPSIS methods to municipal services. Therefore, the summary table of similar studies is shown in Table 1 with the subjects on which the MCDM studies of the authors are applied.

The FAHP and FTOPSIS methods used in this study are important methods used in multi-criteria decision making. Jain et al. [7] obtained the optimization of the performance parameters of a fixed VCR engine fueled with diesel-jatropha mixtures using the hybrid FAHP-FTOPSIS method. They used the FAHP approach to determine the fuzzy weight of each PDA and calculated the sequencing with the FTOPSIS approach. Yucesan and Gul [8] applied the FAHP, FTOPSIS and SWOT methods to work to determine the factors affecting productivity in the mining industry. To prioritize the strategies used in the study, firstly FAHP was used to weight the criterion with expert opinions. Then, they gave priority to strategies with the FTOPSIS method. Manivel and Ranganathan [9] worked on supplier selection considering that supplier selection was important in the hospital pharmacy. They concluded that multi-criteria selection methods would be suitable for this selection. They were interviewed with the authorized person and analyzed with five criteria and ranked among the alternatives by FAHP and FTOPSIS methods. Amalnick et al. [10] have applied multi-criteria decision-making methods to a high-tech industry for resource allocation. In this application, machine tools and human resources FAHP and FTOPSIS methods have been used and aimed to reach the selection that can achieve high efficiency with limited resources. Kamble and Parveen [11] used FAHP and FTOPSIS techniques for personnel selection problem. They used 7 different criteria for 7 candidates in personnel selection. The criteria were weighted by the fuzzy AHP method, and the candidates were ranked by the fuzzy TOPSIS method. Boutkhoum et al. [12] proposed a hybrid decision-making methodology based on FAHP and FTOPSIS to evaluate, sort and select the most suitable cloud solutions to host and manage big data projects. Researchers have provided a decision-making approach to help users choose the cloud

Table 1 Literature criteria about municipal services

\begin{tabular}{|c|c|c|c|c|c|c|c|c|c|}
\hline Researchers & Methodology & Finance & Environment & Public relation & Social benefit & Culture & City planning & $\begin{array}{l}\text { Transporta- } \\
\text { tion }\end{array}$ & Education \\
\hline Bostancı [2] & FAHP & & $\checkmark$ & & $\checkmark$ & $\checkmark$ & $\checkmark$ & $\checkmark$ & \\
\hline Kılıç [3] & VIKOR & $\checkmark$ & $\checkmark$ & $\checkmark$ & & $\checkmark$ & & & $\checkmark$ \\
\hline $\begin{array}{c}\text { Bozdoğan } \\
\text { et al. [1] }\end{array}$ & $\begin{array}{r}\text { AHP and } \\
\text { TOPSIS }\end{array}$ & $\checkmark$ & & & & & & & \\
\hline $\begin{array}{l}\text { Zarei and } \\
\quad \text { Talebnia [5] }\end{array}$ & GAHP-VIKOR & $\checkmark$ & & $\checkmark$ & & & & & \\
\hline Ansari et al. [6] & $\begin{array}{l}\text { FUZZY } \\
\text { MCDM-BSC }\end{array}$ & $\checkmark$ & & $\checkmark$ & & & & & \\
\hline $\begin{array}{l}\text { Çiçek and Dik- } \\
\text { men [4] }\end{array}$ & GRA & $\checkmark$ & & & $\checkmark$ & $\checkmark$ & $\checkmark$ & & \\
\hline
\end{tabular}


solutions they prefer the most. They determined the criteria with the decision-makers using the affinity diagram. Then, they used a FAHP method to assign the weight of importance for each criterion, due to the varying importance of the selected criteria. With the FTOPSIS method, they used these weighted criteria as input to evaluate and measure performance. At the end of the study, with the sensitivity analysis, in the last step, they evaluated the effect of the criteria weights on the final rankings of the alternatives. Hadavi and Mirabi [13] have identified a fuzzy performance evaluation model based on financial and non-financial indicators for the banking sector to use. In this model, they used FAHP and FTOPSIS methods by integrating with balanced scorecards and SWOT analysis indices. Shafii et al. [14] aimed to measure the performance of hospital managers and used FAHP and FTOPSIS methods to select qualified managers, identify strengths and weaknesses in performance and ensure continuous improvements. To measure the performance of the hospital managers, they determined 19 sub-criteria and 5 main criteria such as functional, professional, organizational, individual and human.

\section{Methodology}

Fuzzy multiple attribute decision-making (FMADM) methods are the methods developed to eliminate the problems encountered in evaluating the acquisitive importance of qualifications and the performance scores of alternatives regarding qualifications. Traditional MADM methods cannot effectively address problems with inaccurate information. To overcome this difficulty, the fuzzy set theory is used and adopted here [15]. Fuzzy AHP and fuzzy TOPSIS were discussed separately, and the data sets used in the solutions were considered as different from each other.

\subsection{Fuzzy analytical hierarchy process method}

The AHP method has been widely used in multi-criteria decision making [16]. It is easy to use, understandable and widely used multi-criteria decision-making method. AHP facilitates complex decision-making problems because it treats alternatives hierarchically. AHP solves problems by creating a functional hierarchy and prioritizes the criteria so that the most appropriate alternative is selected. Equivocalness is a common problem in all decision-making progress. Fuzzy sets have been used to eliminate this ambition in the problems because decision-makers often give uncertain answers. With the fuzzy AHP, the optimist/ pessimist rating attitude of decision-makers is taken into account; linguistic values, which are usually characterized by triangular fuzzy numbers, are recommended to assess preference ratings instead of conventional numerical equivalence method [15]. The use of linguistic expressions makes it easier for decision-makers to make assessments.

According to the decision maker's opinion, the degree of superiority of certain factor over other factor is determined and a pairwise comparison matrix is obtained under these grades. For fuzzy AHP, Chang's (1992) fuzzy extent analysis method is generally considered. Fuzzy AHP method begins by setting the comparison matrix with the determination of the priorities of the experts using the fuzzy scale from Table 2 .

$\tilde{c}_{k}=\left|\begin{array}{cccc}1 & \tilde{c}_{12} & \ldots & \tilde{c}_{1 n} \\ \tilde{c}_{21} & 1 & \ldots & \tilde{c}_{2 n} \\ \cdot & \cdot & \ldots & \cdot \\ \cdot & \cdot & \ldots & \cdot \\ \cdot & \cdot & \ldots & \cdot \\ \tilde{c}_{n 1} & \tilde{c}_{n 2} & \ldots & 1\end{array}\right|, \quad k=1,2,3, \ldots, k$

According to Chang's extent analysis method, which is designated as $X=\left\{x_{1}, x_{2} \ldots, x_{n}\right\}$ an object set and $U=\left\{u_{1}, u_{2} \ldots, u_{m}\right\}$ a goal set, each goal $g_{i}$ is taken and
Table 2 Fuzzy scales

\begin{tabular}{llll}
\hline Linguistic terms & Crisp scale & Triangular fuzzy scale & $\begin{array}{l}\text { Triangular fuzzy } \\
\text { reciprocal scale }\end{array}$ \\
\hline Equal importance (E) & 1 & $(1,1,1)$ & $(1 / 1,1 / 1,1 / 1)$ \\
Moderate importance (M) & 3 & $(1,3,5)$ & $(1 / 5,1 / 3,1 / 1)$ \\
Strong importance (S) & 5 & $(3,5,7)$ & $(1 / 7,1 / 5,1 / 3)$ \\
Very strong importance (VS) & 7 & $(5,7,9)$ & $(1 / 9,1 / 7,1 / 5)$ \\
Extreme importance (EX) & 9 & $(7,9,9)$ & $(1 / 9,1 / 9,1 / 7)$ \\
Intermediate values between two & 2 & $(1,2,3)$ & $(1 / 3,1 / 2,1)$ \\
adjacent judgments (IV) & 4 & $(3,4,5)$ & $(1 / 5,1 / 4,1 / 3)$ \\
& 6 & $(5,6,7)$ & $(1 / 9,1 / 8,1 / 5)$ \\
& 8 & $(7,8,9)$ & \\
\hline
\end{tabular}


each extent analysis is applied in order. Thus, the m extent analysis value for each target is obtained as shown below.

$M_{g_{i}}^{1} M_{g_{i}}^{2}, \ldots, M_{g_{i}^{\prime}}^{m} \quad i=1,2,3 \ldots, n$

All the parameters $M_{g^{\prime}}^{j}$ where $j=1,2,3, \ldots, n$, represent fuzzy numbers $\mathrm{l}, \mathrm{m}$ and $\mathrm{u}$ which indicate the smallest possible value, the most expected value and the largest possible value, respectively.

Step 1: The fuzzy synthetic extent value according to ith description is defined as follows:

$S_{i}=\sum_{j=1}^{m} M_{g_{i}}^{j} *\left[\sum_{i=1}^{n} \sum_{j=1}^{m} M_{g_{i}}^{j}\right]^{-1}$

To obtain $\sum_{j=1}^{m} M_{g_{i^{\prime}}}^{j}$ it performs the fuzzy addition of the $m$ extent analysis for a given matrix such that

$\sum_{j=1}^{m} M_{g_{i}}^{j}=\left(\sum_{j=1}^{m} \iota_{j}, \sum_{j=1}^{m} m_{j}, \sum_{j=1}^{m} u_{j}\right)$

To find $\left[\sum_{i=1}^{n} \sum_{j=1}^{m} M_{g_{i}}^{j}\right]^{-1}$, fuzzy addition operation is performed on $M_{g_{i}}^{j}(j=1,2, \ldots m)$ values

$\sum_{i=1}^{n} \sum_{j=1}^{m} M_{g_{i}}^{j}=\left(\sum_{j=1}^{n} l_{j}, \sum_{j=1}^{n} m_{j}, \sum_{j=1}^{n} u_{j}\right)$

The last step of this step is to calculate the inverse of the vector with the formula below

$\left[\sum_{i=1}^{n} \sum_{j=1}^{m} M_{g_{i}}^{j}\right]^{-1}=\left(\frac{1}{\sum_{i=1}^{n} u_{i}}+\frac{1}{\sum_{i=1}^{m} m_{i}}+\frac{1}{\sum_{i=1}^{n} l_{i}}\right)$

Step 2: The degree of possibility of $M_{2}\left(I_{2}, m_{2}, u_{2}\right) \geq M_{1}\left(I_{1}, m_{1}, u_{1}\right)$ is defined as

$V\left(M_{2} \geq M_{1}\right)=\sup _{y \geq x}\left[\min \left(\mu_{M_{1}}(x), \mu_{M_{2}}(y)\right]\right.$

$M_{1}\left(I_{1}, m_{1}, u_{1}\right)$ and $M_{2}\left(I_{2}, m_{2}, u_{2}\right)$ are triangular fuzzy numbers $V\left(M_{2} \geq M_{1}\right)$;

$V\left(M_{2} \geq M_{1}\right)=\operatorname{hgt}\left(M_{1} \cap M_{2}\right)=\mu M_{2}(d)$

$V\left(M_{2} \geq M_{1}\right)= \begin{cases}1 ; & m_{2} \geq m_{1} \\ 0 ; & m_{2} \geq m_{1} \\ \frac{\left(I_{1}-u_{2}\right)}{\left(m_{2}-u_{2}\right)-\left(m_{1}-l_{1}\right)} ; & \text { otherwise }\end{cases}$

Step 3: The degree of possibility for a fuzzy number to be great than $k$ fuzzy numbers $M_{i}(i=1,2, \ldots, k)$ can be defined by
$V\left(M \geq M_{1}, M_{2}, \ldots, M_{k}\right)=\min V\left(M \geq M_{i}\right), \quad i=1,2, \ldots, k$

Assume that

$\left(d^{\prime}\left(A_{i}\right)=\min V\left(S_{i} \geq S_{k}\right), k=1,2, \ldots, n ; \quad k \neq i\right.$

Then, the weight vector is given by

$W^{\prime}=\left(d^{\prime}\left(A_{1}\right), d^{\prime}\left(A_{2}\right), \ldots, d^{\prime}\left(A_{n}\right)\right)^{T}$

where $A_{i},(i=1,2, \ldots, n)$ represent $n$ elements.

Step 4: Normalize the weight vector by normalization

$W=\left(d\left(A_{1}\right), d\left(A_{2}\right), \ldots, d\left(A_{n}\right)\right)^{T}$

where $W$ is not a fuzzy number

\subsection{Fuzzy technique for order preference by similarity to ideal solution}

Fuzzy TOPSIS is an alternative selection concept used in multi-criteria decision-making methods. This method attempts to choose alternatives that have the closest distance to the positive ideal solution and the furthest distance to the negative ideal solution. The positive ideal solution maximizes the benefit criteria and minimizes the cost criteria, while the negative ideal solution maximizes the cost criteria and minimizes the benefit criteria so that the TOPSIS method selects an alternative that most closely resembles the ideal solution [17].

In this study, the fuzzy TOPSIS method was used in addition to the fuzzy AHP method. The operation of this method is explained step by step below [18].

Step 1: Criteria and alternatives are rated. We assume that we have a decision group with $K$ members. The fuzzy rating of the kth decision-maker about alternative $A_{i}$ w.r.t. criterion $C_{j}$ is denoted as $\tilde{x}_{i j}^{k}=\left(a_{i j}^{k}, b_{i j}^{k} c_{i j}^{k}\right)$, and the weight of criterion $C_{j}$ is denoted as $\tilde{w}_{j}^{k}=\left(w_{j 1}^{k}, w_{j 2}^{k}, w_{j 3}^{k}\right)$.

Step 2: Calculate total fuzzy values for alternatives and total fuzzy weights for criteria by using Table 3 [19].

The aggregated fuzzy rating $\tilde{x}_{i j}^{k}=\left(a_{i j}, b_{i j}, c_{i j}\right)$ of $i$ th alternative w.r.t. $j$ th the criterion is obtained as follows:

$a_{i j}=\min \left\{a_{i j}^{k}\right\}, b_{i j}=\frac{1}{K} \sum_{k=1}^{K} b_{i j}^{k} c_{i j}=\max \left\{c_{i j}^{k}\right\}$

The aggregated fuzzy weight $\tilde{w}_{j}=\left(w_{j 1}, w_{j 2}, w_{j 3}\right)$ for the criterion $C_{j}$ is calculated by formulas: 
Table 3 Triangular fuzzy scale of preferences

\begin{tabular}{llll}
\hline Linguistic terms & Crisp scale & Triangular fuzzy scale & $\begin{array}{l}\text { Triangular fuzzy } \\
\text { reciprocal scale }\end{array}$ \\
\hline Equal importance (E) & 1 & $(1,1,1)$ & $(1 / 1,1 / 1,1 / 1)$ \\
Moderate importance (M) & 3 & $(1,3,5)$ & $(1 / 5,1 / 3,1 / 1)$ \\
Strong importance (S) & 5 & $(3,5,7)$ & $(1 / 7,1 / 5,1 / 3)$ \\
Very strong importance (VS) & 7 & $(5,7,9)$ & $(1 / 9,1 / 7,1 / 5)$ \\
Extreme importance (EX) & 9 & $(7,9,9)$ & $(1 / 9,1 / 9,1 / 7)$ \\
Intermediate values between two & 2 & $(1,2,3)$ & $(1 / 3,1 / 2,1)$ \\
adjacent judgments (IV) & 4 & $(3,4,5)$ & $(1 / 5,1 / 4,1 / 3)$ \\
& 6 & $(5,6,7)$ & $(1 / 9,1 / 6,1 / 5)$ \\
& 8 & $(7,8,9)$ & \\
\hline
\end{tabular}

$d_{i}^{*}=\sum_{j=1}^{n} d\left(\tilde{v}_{i j}, \tilde{v}_{j}^{*}\right), d_{i}^{-}=\sum_{j=1}^{n} d\left(\tilde{v}_{i j}, \tilde{v}_{j}^{-}\right)$

Step 3: Calculate the normalized fuzzy decision matrix. The normalized fuzzy decision matrix is $\tilde{R}=\left[\tilde{r}_{i j}\right]$, where

$\tilde{r}_{i j}=\left(\frac{a_{i j}}{c_{j}^{*}}, \frac{b_{i j}}{c_{j}^{*}}, \frac{c_{i j}}{c_{j}^{*}}\right)$ and $c_{j}^{*}=\max \left\{c_{i j}\right\}$ (benefit criteria)

$\tilde{r}_{i j}=\left(\frac{a_{j}^{-}}{c_{i j}}, \frac{a_{j}^{-}}{b_{i j}}, \frac{a_{j}^{-}}{a_{i j}}\right)$ and $c_{j}^{-}=\min \left\{a_{i j}\right\}$ (cost criteria)

Step 4: Calculate the weighted normalized fuzzy decision matrix. The weighted normalized fuzzy decision matrix is

$\tilde{V}=\left(\tilde{v}_{i j}\right)$, where $\tilde{v}_{i j}=\tilde{r}_{i j} \times w_{j}$

Step 5: Calculate fuzzy positive ideal solution (FPIS) and fuzzy negative ideal solution (FNIS)

$A^{*}=\left(\tilde{v}_{1}^{*}, \tilde{v}_{2}^{*}, \ldots \tilde{v}_{n}^{*}\right)$ where $\tilde{v}_{j}^{*}=\max \left\{v_{i j a}\right\} ;$

$A^{-}=\left(\tilde{v}_{1}^{-}, \tilde{v}_{2}^{-}, \ldots, \tilde{v}_{n}^{-}\right)$, where $\tilde{v}_{j}^{-}=\max \left\{v_{i j 1}\right\}$

Step 6: Calculate the distance between FPIS and FNIS with each alternative. Linguistic values are used for evaluation scores of alternatives and weights of criteria, the fuzzy

TOPSIS approach changes. If $\tilde{x}=\left(a_{1}, b_{1}, c_{1}, d_{1}\right), \tilde{y}=\left(a_{2}, b_{2}, c_{2}, d_{2}\right)$ are two trapezoidal FNs, then

$d(\tilde{x}, \tilde{y})=\sqrt{\frac{1}{4}\left[\left(a_{1}-a_{2}\right)^{2}+\left(b_{1}-b_{2}\right)^{2}+\left(c_{1}-c_{2}\right)^{2}+\left(d_{1}-d_{2}\right)^{2}\right]}$

Let

be the distance from each alternative $A_{i}$ to the FPIS and the FNIS, respectively.

Step 7: Calculate the closeness coefficient $C C_{i}$ for each alternative

$C C_{i}=\frac{d_{i}^{-}}{d_{i}^{-}+d_{i}^{*}}$

Step 8: Rank the alternatives according to the closeness to the best alternative

\section{Case study}

The form containing criteria and alternatives was created, and in addition to this form, a binary comparison matrix to be used by experts was added. Data related to the study were obtained by this form which implements five experts who are working in the public services units in a municipality in Turkey. These experts were asked to fill the form to determine the binary comparison values for alternatives ( $A 1, A 2, A 3, A 4$ and $A 5)$ and criteria $(C 1, C 2, C 3, C 4, C 5$ and C6) among themselves according to a binary comparison matrix which is given. They have chosen fuzzy numbers corresponding to equal importance $(\mathrm{E})$, moderate importance (M), strong importance (S), very strong importance (VS), extreme importance (EX) and intermediate values between two adjacent judgments (IV) in Table 3.

The hierarchy for the selection of the best service is shown in Fig. 1. We have five main criteria in the hierarchical structure and 6 alternatives based on them. According to the expert opinion, municipal services are combined as "educational services, infrastructure services, social and cultural services, recycling and waste management services, parks, gardens, landscape services." And a description of each of the criteria which are used to evaluate 


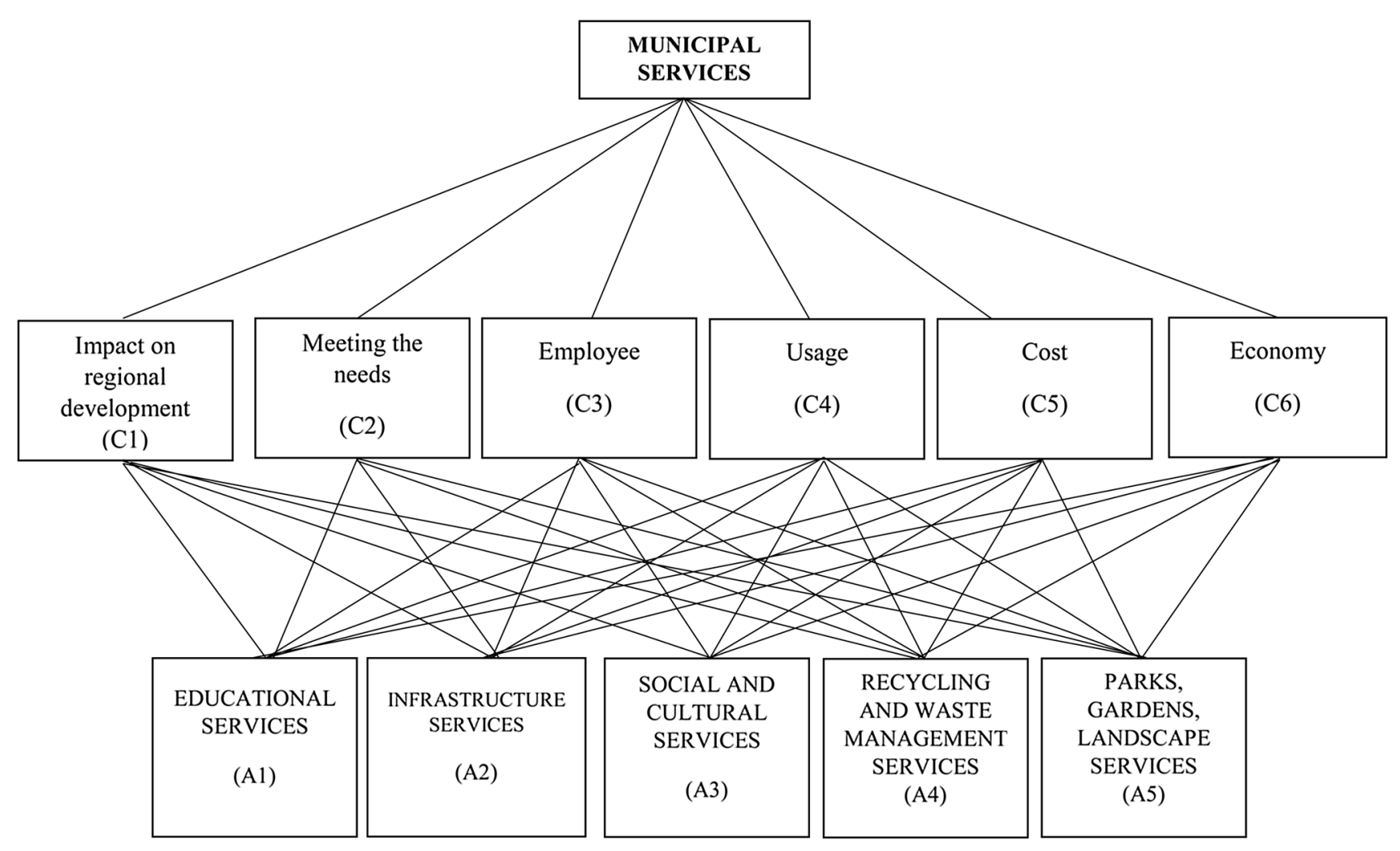

Fig. 1 The relationship between the criteria and the municipal services

municipal services is shown in Table 4. The criteria shown in Table 4 were determined by the common opinion of the authors, taking into literature review (Table 1) about municipal services and expert opinions.

In the following, the methods of fuzzy analytic hierarchy process and hierarchical fuzzy TOPSIS have been applied for evaluating and selecting the best beneficial service among the five municipal services [20].

\subsection{The solution of fuzzy analytical hierarchy process model}

The primary purpose of the study is to provide an effective and efficient municipal service to citizens under constraints such as limited time, consumable resources and limited workforce as a result of the ranking of municipal services.
For this reason, as stated in Table 1, decision criteria were established in the light of the information obtained from the literature and decision-makers. By meeting with the decision-makers determined for the purpose of evaluating the determined criteria, the purpose and expectations of the study were mentioned and information was given on how to fill the questionnaire used. A 3-week study was carried out to fill these interviews and questionnaires, and the data obtained were then tested and interpreted with the proposed approaches. In this context, firstly, alternatives were prioritized with the fuzzy AHP approach. For this purpose, first of all, comparisons are determined between the criterion and alternatives. The first stage of problem-solving is the comparison of the weight of the criteria with each other and with alternatives. These comparisons were made according to the triangular fuzzy numbers in Table 3 [21]. The binary

Table 4 A description of each of the criteria which are used to evaluate municipal services

Impact on regional development (C1)

Meeting the needs (C2)

Employee (C3)

Usage (C4)

Cost (C5)

Economy (C6)
This criterion refers to the level of influence of the people and the region on the level of education and culture

This criterion refers to the level of services that meet the needs of the people

This criterion refers to the number of people employed in the implementation of services This criterion refers to the number of people who benefit from services

This criterion refers to the cost of providing the service at a certain time

This criterion refers to the amount and the contribution of the country's economy 
comparison matrix is created for criteria and alternatives by taking the average of the fuzzy comparison numbers taken from the form filled by these five experts used as a decisionmaker. As a result of these evaluations, Table 5 shows the final binary comparisons.

The synthesis values are calculated according to the extended analysis method. Using the data in Table 5, the synthesis values of the main criterion are calculated according to Eq. (1) as follows:

$$
\begin{aligned}
& S_{C 1}=(3.73,7,10.67) \times(40.63,61.23,85.20)^{-1}=(0.04,0.12,0.26) \\
& S_{C 2}=(0.13,0.27,0.54) \\
& S_{C 3}=(0.16,0.34,0.69) \\
& S_{C 4}=(0.08,0.16,0.34) \\
& S_{C 5}=(0.04,0.07,0.16) \\
& S_{C 6}=(0.02,0.04,0.1)
\end{aligned}
$$

The obtained values are compared with fuzzy numbers by using Eq. (7).

$$
\begin{array}{lll}
V\left(S_{1} \geq S_{2}\right)=0.455 & V\left(S_{2} \geq S_{1}\right)=1 & V\left(S_{3} \geq S_{1}\right)=1 \\
V\left(S_{1} \geq S_{3}\right)=0.301 & V\left(S_{2} \geq S_{3}\right)=0.837 & V\left(S_{3} \geq S_{2}\right)=1 \\
V\left(S_{1} \geq S_{4}\right)=0.801 & V\left(S_{2} \geq S_{4}\right)=1 & V\left(S_{3} \geq S_{4}\right)=1 \\
V\left(S_{1} \geq S_{5}\right)=1 & V\left(S_{2} \geq S_{5}\right)=1 & V\left(S_{3} \geq S_{5}\right)=1 \\
V\left(S_{1} \geq S_{6}\right)=1 & V\left(S_{2} \geq S_{6}\right)=1 & V\left(S_{3} \geq S_{6}\right)=1
\end{array}
$$

$V\left(S_{4} \geq S_{1}\right)=1 \quad V\left(S_{5} \geq S_{1}\right)=0.743 V\left(S_{6} \geq S_{1}\right)=0.41$

$V\left(S_{4} \geq S_{2}\right)=0.66 \quad V\left(S_{5} \geq S_{2}\right)=0.136 V\left(S_{6} \geq S_{2}\right)=0$

$V\left(S_{4} \geq S_{3}\right)=0.499 V\left(S_{5} \geq S_{3}\right)=0 \quad V\left(S_{6} \geq S_{3}\right)=0$

$V\left(S_{4} \geq S_{5}\right)=1 \quad V\left(S_{5} \geq S_{4}\right)=0 \quad V\left(S_{6} \geq S_{4}\right)=0.13$

$V\left(S_{4} \geq S_{6}\right)=0 \quad V\left(S_{5} \geq S_{6}\right)=0 \quad V\left(S_{6} \geq S_{5}\right)=0.65$
These values are obtained by using Eq. (8), and priority values are obtained:

$$
\begin{aligned}
& d^{\prime}(C 1)=\operatorname{Min}(0.455,0.301,0.801,1,1)=0.301 \\
& d^{\prime}(C 2)=\operatorname{Min}(1,0.837,1,1,1)=0.837 \\
& d^{\prime}(C 3)=\operatorname{Min}(1,1,1,1,1)=1 \\
& d^{\prime}(C 4)=\operatorname{Min}(1,0.66,0.499,1,1)=0.499 \\
& d^{\prime}(C 5)=\operatorname{Min}(0.743,0.136,0,0,0)=0
\end{aligned}
$$

As a result of the normalization of these values, according to the criteria, the weighted value is calculated as

$W=(0.114,0.317,0.379,0.190,0,0)$

It is calculated for alternative evaluation matrices by following the same procedures and weights. Evaluation matrices are created by binary comparisons of five alternative supplier ratings based on all criteria. Similarly, the fuzzy numbers of supplier alternativratings of the supplier by criteria are graded, and the weight vectors of alternatives for each criterion give the results in Table 6 .

$W$ values obtained from Table 6 are 0.2684 for Alternative 1 (educational services), 0.3538 for Alternative 2 (infrastructure services) and 0.1441 for Alternative 3 (social and cultural services), 0.0792 for Alternative 4 (recycling and waste management services) and 0.1546 for Alternative 5 (Parks, gardens, landscape services). When the alternatives weighted according to the big to small criteria are listed, it is seen that the largest $W$ value is A2 which is infrastructure services. This result shows that the "infrastructure services" is the priority in the selection of the service using "Impact on regional development," "Meeting the needs,"
Table 5 Binary comparison matrix of main criteria expressed with fuzzy numbers

\begin{tabular}{lrrrrrrr}
\hline & \multicolumn{2}{c}{ C1 } & \multicolumn{2}{c}{ C3 } & \multicolumn{2}{c}{ C4 } & \multicolumn{1}{c}{ C6 } \\
\hline C1 & $(1,1,1)$ & $(1 / 5,1 / 4,1 / 3)$ & $(1 / 5,1 / 4,1 / 3)$ & $(1 / 3,1 / 2,1)$ & $(1,2,3)$ & $(1,3,5)$ \\
C2 & $(3,4,5)$ & $(1,1,1)$ & $(1 / 3,1 / 2,1)$ & $(1,2,3)$ & $(3,4,5)$ & $(3,5,7)$ \\
C3 & $(3,4,5)$ & $(1,2,3)$ & $(1,1,1)$ & $(1,3,5)$ & $(3,5,7)$ & $(5,6,7)$ \\
C4 & $(1,2,3)$ & $(1 / 3,1 / 2,1)$ & $(1 / 5,1 / 3,1)$ & $(1,1,1)$ & $(1,2,3)$ & $(3,4,5)$ \\
C5 & $(1 / 3,1 / 2,1)$ & $(1 / 5,1 / 4,1 / 3)$ & $(1 / 7,1 / 5,1 / 3)$ & $(1 / 3,1 / 2,1)$ & $(1,1,1)$ & $(1,2,3)$ \\
C6 & $(1 / 5,1 / 3,1)$ & $(1 / 7,1 / 5,1 / 3)$ & $(1 / 7,1 / 6,1 / 5)$ & $(1 / 5,1 / 4,3)$ & $(1 / 3,1 / 2,1)$ & $(1,1,1)$ \\
\hline
\end{tabular}

Table 6 Weights of the alternatives according to criteria

\begin{tabular}{llllllll}
\hline & C1 & C2 & C3 & C4 & C5 & C6 & $W$ \\
\hline & 0.1136 & 0.3788 & 0.3182 & 0.1894 & 0 & 0 & \\
A1 & 0.5882 & 0.2 & 0.2088 & 0.3103 & 0.2233 & 0 & 0.2684 \\
A2 & 0.1294 & 0.3226 & 0.3367 & 0.5747 & 0.3511 & 0 & 0.3538 \\
A3 & 0.2824 & 0.1516 & 0.1684 & 0 & 0.1322 & 1 & 0.1441 \\
A4 & 0 & 0.0903 & 0.1246 & 0.0172 & 0 & 0 & 0.0792 \\
A5 & 0 & 0.2355 & 0.1616 & 0.0977 & 0.2934 & 0 & 0.1546 \\
\hline
\end{tabular}


"Employee," "Usage," "Cost," "Economy" criteria with the fuzzy AHP method.

\subsection{The solution of fuzzy technique for order preference by similarity to ideal solution model}

In this section, the FTOPSIS method is proposed for service selection of the municipality. The explanations for the fuzzy TOPSIS method are given step by step above. The calculations made by using the above steps in line with the problem of municipal service selection discussed are given in the tables below. Firstly, a fuzzy weight matrix using linguistic expressions in Table 5 was determined according to the opinions of five experts working in the municipality. The fuzzy values obtained from the form filled by experts are shown in Table 7.

The weights obtained as a result of alternative evaluations in terms of fuzzy performance evaluation are normalized. Normalization is addressed in two cases: benefit and cost. In this study, C3, employee, and C5, cost, are cost criteria, and $\mathrm{C} 1$, impact on regional development, $\mathrm{C} 2$, meeting the needs, $\mathrm{C} 4$, usage, and C6, economy, are determined as beneficial criteria.

From Eqs. 13-14, the normalized matrix is shown in Table 8.

The fuzzy positive ideal solution $\mathrm{A}^{+}$and the fuzzy negative ideal solution $A^{-}$are determined and are shown in Table 9.

In the last step, the index $C C_{i}$ is calculated for each criterion by Eq. 20. The calculation of the distance between FPIS and FNIS with each alternative to reach the value of $C C_{i}$ is shown as follows (Tables 10,11 );

$C C_{1}=\frac{3.356}{7.937+3.356}$

The index $C_{C}$ for other alternatives and according to $C C_{i}$ the rank of alternatives are shown in Table 12.

The alternative whose $C C_{i}$ value is closest to 1 is determined as the best alternative which is A2-infrastructure services presented in Fig. 2 [22].

Table 7 The aggregated fuzzy rating

\begin{tabular}{lllllll}
\hline & Very strong & $\begin{array}{l}\text { Strong } \\
\text { C1 }\end{array}$ & $\begin{array}{l}\text { Strong } \\
\text { C3 }\end{array}$ & $\begin{array}{l}\text { Moderate } \\
\text { C4 }\end{array}$ & $\begin{array}{l}\text { Moderate } \\
\text { C5 }\end{array}$ & $\begin{array}{l}\text { Intermediate } \\
\text { C6 }\end{array}$ \\
\hline A1 & $(3,5.33,9)$ & $(1,3.66,5)$ & $(5,6.33,9)$ & $(3,4.33,7)$ & $(1,3.67,5)$ & $(3,5.33,7)$ \\
A2 & $(5,7.33,9)$ & $(5,6.33,9)$ & $(1,3.67,5)$ & $(3,5.67,9)$ & $(1,3.67,5)$ & $(5,7.33,9)$ \\
A3 & $(3,5.33,7)$ & $(3,4.33,7)$ & $(3,5.67,9)$ & $(1,4,7)$ & $(3,4.33,7)$ & $(3,4.33,7)$ \\
A4 & $(3,6,9)$ & $(3,4.33,7)$ & $(1,3.33,5)$ & $(1,3.33,5)$ & $(1,3.33,5)$ & $(5,6.33,9)$ \\
A5 & $(1,4,7)$ & $(5,7,9)$ & $(1,3.67,5)$ & $(5,7,9)$ & $(1,3.67,5)$ & $(1,3.33,5)$ \\
\hline
\end{tabular}

Table 8 Normalized matrix

\begin{tabular}{lllllll}
\hline & C1 & C2 & C3 & C4 & C5 & C6 \\
\hline A1 & $(0.33,0.593,1)$ & $(0.111,0.407,0.556)$ & $(0.111,0.158,0.200)$ & $(0.333,0.481,0.778)$ & $(0.2,0.273,1)$ & $(0.333,0.593,0.778)$ \\
A2 & $(0.556,0.815,1)$ & $(0.556,0.704,1)$ & $(0.2,0.273,1)$ & $(0.33,0.63,1)$ & $(0.2,0.273,1)$ & $(0.556,0.815,1)$ \\
A3 & $(0.333,0.593,0.778)$ & $(0.333,0.481,0.778)$ & $(0.111,0.176,0.333)$ & $(0.111,0.444,0.778)$ & $(0.143,0.231,0.333)$ & $(0.333,0.481,0.778)$ \\
A4 & $(0.333,0.667,1)$ & $(0.333,0.481,0.778)$ & $(0.2,0.3,1)$ & $(0.111,0.37,0.556)$ & $(0.2,0.3,1)$ & $(0.556,0.704,1)$ \\
A5 & $(0.111,0.444,0.778)$ & $(0.556,0.778,1)$ & $(0.2,0.273,1)$ & $(0.556,0.778,1)$ & $(0.2,0.273,1)$ & $(0.111,0.370,0.556)$ \\
\hline
\end{tabular}

Table 9 Weighted normalized matrix and fuzzy positive ideal solution $\mathrm{A}^{+}$and the fuzzy negative ideal solution $\mathrm{A}^{-}$

\begin{tabular}{lllllll}
\hline & C1 & C2 & C3 & C4 & C5 & C6 \\
\hline A1 & $(1.667,4.148,9)$ & $(0.33,2.037,3.889)$ & $(0.333,0.789,1.4)$ & $(0.333,1.44,3.889)$ & $(0.2,0.545,3)$ & $(0.333,1.185,2.333)$ \\
A2 & $(2.778,5.704,9)$ & $(1.667,3.519,7)$ & $(0.6,1.364,79$ & $80.33,1.889,59$ & $80.2,0.545,3)$ & $(0.556,1.630,3)$ \\
A3 & $(1,667,4.148,7)$ & $(1,2.407,5.444)$ & $(0.333,0.882,2.333)$ & $(0.111,1.333,3.889)$ & $(0.143,0.462,1)$ & $(0.333,0.963,2.333)$ \\
A4 & $(1.667,4.667,9)$ & $(1,2.407,5.44)$ & $(0.600,1.5,7)$ & $(0.111,1.111,2.778)$ & $(0.2,0.6,3)$ & $(0.556,1.407,3)$ \\
A5 & $(1.667,4.667,9)$ & $(1.667,3889,7)$ & $(0.6,1.364,7)$ & $(0.556,2.333,5)$ & $(0.2,0.545,3)$ & $(0.556,1.407,3)$ \\
A* & $(2.778,5.704,9)$ & $(1.667,3.889,7)$ & $(0.6,1.5,7)$ & $(0.556,2.33,5)$ & $(0.2,0.6,3)$ & $(0.556,1.630,3)$ \\
A- & $(0.556,3.111,7)$ & $(0.333,2.037,3.889)$ & $(0.333,0.789,1.4)$ & $(0.111,1.111,2.778)$ & $(0.143,0.462,1)$ & $(0.111,0.741,1.667)$ \\
\hline
\end{tabular}


Table 10 Closeness coefficients to aspired levels among different services
Table 11 Closeness coefficients to aspired levels among different services

\begin{tabular}{|c|c|c|c|c|c|c|c|}
\hline \multicolumn{7}{|c|}{ Distance from FPIS } & \multirow{2}{*}{$\frac{d_{i}^{+}}{7.937}$} \\
\hline $\mathrm{A} 1$ & 1.104 & 2.228 & 3.263 & 0.831 & 0.031 & 0.480 & \\
\hline $\mathrm{A} 2$ & 0 & 0.214 & 0.079 & 0.287 & 0.031 & 0 & 1 \\
\hline $\mathrm{A} 3$ & 1.597 & 1.299 & 2.722 & 0.9 & 1.158 & 0.559 & 8.236 \\
\hline A4 & 0.877 & 1.299 & 0 & 1.487 & 0 & 0.128 & 3.791 \\
\hline A5 & 0 & 2.228 & 3.254 & 0 & 0.031 & 0.96 & 6 \\
\hline
\end{tabular}

\begin{tabular}{|c|c|c|c|c|c|c|c|}
\hline \multicolumn{7}{|c|}{ Distance from FNIS } & \multirow{2}{*}{$\frac{d_{i}^{-}}{3.356}$} \\
\hline $\mathrm{A} 1$ & 1.450 & 0 & 0 & 0.744 & 0.682 & 0.480 & \\
\hline $\mathrm{A} 2$ & 2.285 & 2.133 & 3.254 & 3.994 & 1.365 & 0.960 & 13.991 \\
\hline A3 & 0.877 & 1 & 0.542 & 1.284 & 0.654 & 0.426 & 4.783 \\
\hline A4 & 1.597 & 1 & 3.263 & 4.001 & 0 & 0.898 & 10.760 \\
\hline A5 & 4.434 & 4.722 & 4.132 & 3.994 & 1.487 & 0 & 18.769 \\
\hline
\end{tabular}

Table 12 The index $\mathrm{CC} i$ and the rank of alternatives

\begin{tabular}{lll}
\hline & $C C_{i}$ & Rank \\
\hline A1 & 0.297 & 5 \\
A2 & 0.958 & 1 \\
A3 & 0.367 & 4 \\
A4 & 0.739 & 3 \\
A5 & 0.744 & 2 \\
\hline
\end{tabular}

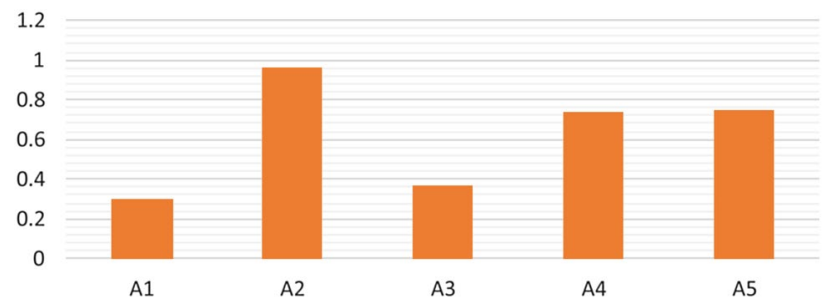

Fig. 2 The ranking of the alternatives based on CCi values

\section{Results and discussions}

This study has been applied for the selection of services to help the municipalities and to enable the municipalities to use their resources efficiently. With this study, municipalities will be able to provide more necessary services to the public together with the resources they have. In the first step of the study, we chose a municipal institution in Turkey and we began to work with the help of five experts who work in this municipality. These five experts were given a form with criteria and alternatives to fill in. By filling out this form, they determined the importance of the criteria and alternatives based on their experience. In line with these comparisons received from

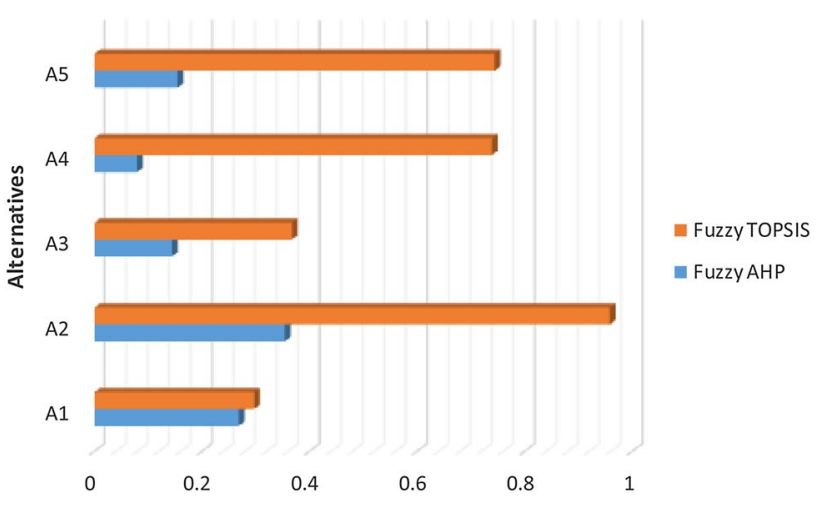

Fig. 3 The comparison of FAHP and FTOPSIS results

experts, binary comparison matrices were obtained and the implementation of these binary comparison matrices and the FAHP and FTOPSIS methods were started. As a result of the above-mentioned FAHP and FTOPSIS transactions, the municipal services ranking was achieved and comparison of the result is presented in Fig. 3.

According to these results, FAHP and FTOPSIS agreed that the most important of the services provided by municipalities is Alternative 2 (A2) - infrastructure services which are exactly in the green zone. The green zone is used in municipal services ranking to show the most important services. A3 - social and cultural services-has the fourth-degree importance according to two methods which are exactly in the red zone. The red zone is used to show the most trivial services in the municipal service ranking. Mayors should pay less attention to services in the red zone. However, the ranking of other services gave different results in two methods. As a result of the FAHP solution, the ranking from the most important service to the least important is $A 2-A 1-A 5-A 3-A 4$ which is shown 
Table 13 Ranking of services according to FAHP

\begin{tabular}{lc}
\hline Green zone & A2-infrastructure services \\
Yellow zone & A4-recycling and waste man- \\
& agement services \\
& A5-parks, gardens, landscape \\
& services \\
Red zone & A1-educational services \\
& A3-social and cultural services \\
\hline
\end{tabular}

Table 14 Ranking of services according to FTOPSIS

\begin{tabular}{lc}
\hline Green zone & A2-infrastructure services \\
Yellow zone & A4-recycling and waste man- \\
& agement services \\
& A5-parks, gardens, landscape \\
& services \\
Red zone & A1-educational services \\
& A3-social and cultural services \\
\hline
\end{tabular}

in Table 13 concerning zones. According to FTOPSIS, the ranking from the most important service to the least important is A2-A5-A4-A3-A1 which is shown in Table 14 concerning zones. The yellow zone is the area between the green zone and the red zone indicating the services that municipal heads must consider after the services in the green area.

\section{Conclusion}

Municipalities have become important and indispensable units of public administration in all countries, while these units provide services such as cleaning, sewage, and garbage collection, transportation to meet the daily needs of the public, on the other hand, such as education, health, and infrastructure, which are of great importance for the development of the country. They also perform many important tasks. In addition to the increasing service demands of the urban population as a result of rapid urbanization, population growth and migration, new service demands of the population emerging with technological development are met by local administrations. This situation increases the importance of local governments day by day. The widespread view of the provision of services by local and nearest administrative units around the world is increasing the importance of local governments. Today, local governments are very important units for providing public goods and services and providing efficient use of resources, reducing transaction costs, and ensuring that the goods and services produced in the public sector are suitable for the local people's preferences. However, there is a fact that because municipalities have limited resources, they cannot give equal importance to all services and therefore municipalities need to know which services are important to other services.

The scientific contributions developed in this research are as follows: this research examined the literature to determine the criteria used in the evaluation of municipal services. And based on the criteria used in other researches, it has ranked the services offered by the municipality with the new criteria determined. These scientific contributions can be used by municipalities and municipal administrators, making it easier for municipalities to choose the services to be provided. Also, the FAHP and FTOPSIS methods used in the literature were not used on municipal services. This study contributes to municipalities to increase their efficiency by choosing priority services.

In this article, the evaluation of the municipal services is discussed. FAHP and FTOPSIS methods were used to compare these services. The five most important services have been selected among the municipal services [23]. These are educational services, infrastructure services, social and cultural services, recycling and waste management services, parks, gardens, landscape services. In assessing services, the impact of services on regional development, meeting the needs of the public, the number of employees in services, the number of people who will benefit from the service, the cost of the service and its contribution to the economy were taken into consideration. Since the traditional AHP and TOPSIS methods do not fully meet the discourse of the decision-makers and the decision-makers are subjective, it has approached the FAHP and FTOPSIS methods to increase the accuracy of the statements of the decision-makers. The study shows that municipalities, especially municipal service managers or mayors, need to give particular importance to infrastructure services to have satisfied public and re-vote. Thanks to this study, municipalities can use their resources efficiently when they have a shortage of resources without reducing public satisfaction.

\section{Future studies}

This study shows how municipal services can be prioritized. In future studies, other services offered by municipalities can be compared among themselves. And the study can be expanded by using all the services provided by the municipality and the most important of all services can be selected. Using the same services as an alternative, it is possible to work with different criteria. In this study, services have been prioritized by using Fuzzy AHP and Fuzzy TOPSIS methods. However, different multi-criteria decision-making techniques such as Fuzzy Promethee and 
Interval Type 2 can be used. Since sub-criteria are not used in this study, the study can be extended with sub-criteria.

Acknowledgements We would like to show our gratitude to the "anonymous" companies for sharing their information and wisdom with us during this research, and we thank our decision-makers for their so-called insights and valuable comments.

\section{Compliance with ethical standards}

Conflict of interest The authors declare no conflict of interest.

\section{References}

1. Bozdoğan T, Tayyar N, Öner Ş (2016) Yeni Kamu Mali Yönetim Anlayişi Perspektifinde Türkiye'de Kamu Kurumlari Mali Performanslarinin Ahp Ve Topsis Yöntemleriyle Değerlendirilmesi. World Account Sci 18:2

2. Bostanci B (2016) Belediye hizmet kalitesinin bulanık AHS ağırlıkları ile nominal değerlemesi. Electron J Map Technol $8(2): 110-130$

3. Kilic HS (2012) The performance evaluation of municipalities with VIKOR: an application among municipalities in Istanbul. Int J Bus Manag Stud 4(1):43-51

4. Çiçek ŞE, Dikmen S, Arslan P (2015) Türkiye'de belediyelerin performansının harcama yapıları açısından analizi. Uluslararası Yönetim İktisat ve İşletme Dergisi 11(24):59-74

5. Zarei S, Talebnia G (2015) Study the areas performance evaluation of regions at Tehran municipality by GAHP-VIKOR techniques. Appl Math Eng Manag Technol 3(1):143-150

6. Ansari M, Hosseini RS, Sharifi M (2016) Evaluating and rating the performance of Qazvin municipalities, using the Balanced Scorecard (BSC) model with Fuzzy Multi-Criteria Decision-Making (FMCDM) approach. Int J Human Cult Stud 3(2):185-197 ISSN 2356-5926

7. Jain SK, Agrawal GD, Gupta K, Misra R (2020) Optimization of performance parameters of stationary VCR diesel engine using hybrid FTOPSIS-FAHP approach. Int J Ambient Energy 1-28

8. Yucesan M, Gul M (2020) Hospital service quality evaluation: an integrated model based on Pythagorean fuzzy AHP and fuzzy TOPSIS. Soft Comput 24(5):3237-3255

9. Manivel P, Ranganathan R (2019) An efficient supplier selection model for hospital pharmacy through fuzzy AHP and fuzzy TOPSIS. Int J Serv Oper Manag 33(4):468-493

10. Amalnick MS, HakimiAsI A, Zanjirani YA, HakimiAsI M (2016) A cloud manufacturing resource allocation by using an integrated FAHP-FTOPSIS approach in high-tech industries. Appl Math Eng Manag Technol 4(1):1-8
11. Kamble PN, Parveen N (2018) An application of integrated fuzzy AHP and fuzzy TOPSIS method for staff selection. J Comput Math Sci 9(9):1161-1169

12. Boutkhoum O, Hanine M, Agouti T, Tikniouine A (2017) A decision-making approach based on fuzzy AHP-TOPSIS methodology for selecting the appropriate cloud solution to manage big data projects. Int J Syst Assur Eng Manag 8(2):1237-1253

13. Hadavi MH, Mirabi VR (2017) Prioritizing SWOT factors using hybrid model of BSC, SWOT, Fuzzy AHP and Fuzzy TOPSIS techniques developed for use in a large Iranian commercial bank. Int Acad Inst Sci Technol 4(2):53-70

14. Shafii M, Hosseini SM, Arab M, Asgharizadeh E, Farzianpour F (2016) Performance analysis of hospital managers using fuzzy AHP and fuzzy TOPSIS: Iranian experience. Glob J Health Sci 8(2):137

15. Gumus AT (2009) Evaluation of hazardous waste transportation firms by using a two step fuzzy-AHP and TOPSIS methodology. Expert Syst Appl 36(2):4067-4074

16. Çalık A, Çizmecioğlu S, Akpınar A (2019) An integrated AHPTOPSIS framework for foreign direct investment in Turkey. $J$ Multi-Criteria Decision Anal 26(5-6):296-307

17. Selim H, Yunusoglu MG, Yılmaz Balaman Ş (2016) A dynamic maintenance planning framework based on fuzzy TOPSIS and FMEA: application in an international food company. Qual Reliab Eng Int 32(3):795-804

18. Kutlu AC, Ekmekçioğlu M (2012) Fuzzy failure modes and effects analysis by using fuzzy TOPSIS-based fuzzy AHP. Expert Syst Appl 39(1):61-67

19. Nădăban S, Dzitac S, Dzitac I (2016) Fuzzy topsis: a general view. Procedia Comput Sci 91:823-831

20. Paksoy T, Pehlivan NY, Kahraman C (2012) Organizational strategy development in distribution channel management using fuzzy AHP and hierarchical fuzzy TOPSIS. Expert Syst Appl 39(3):2822-2841

21. Ertuğrul i (2007) Bulanik Analitik Hiyerarşi Süreci Ve Bir Tekstil Işletmesinde Makine Seçim Problemine Uygulanmasi. Hacettepe Üniversitesi İktisadi ve İdari Bilimler Fakültesi Dergisi 25(1):171-192

22. Özdemir Ai, Seçme NY (2009) Iki aşamali stratejik tedarikçi seçiminin bulanik topsis yöntemi ile analizi. Afyon Kocatepe Üniversitesi İktisadi ve İdari Bilimler Fakültesi Dergisi 11(2):79-112

23. Omar MN, Fayek AR (2016) A TOPSIS-based approach for prioritized aggregation in multi-criteria decision-making problems. J Multi-Criteria Decis Anal 23(5-6):197-209

Publisher's Note Springer Nature remains neutral with regard to jurisdictional claims in published maps and institutional affiliations. 